\title{
A PHENOMENOLOGICAL STUDY OF PREMENSTRUAL SYMPTOMS IN MEDICAL AND NURSING STUDENTS
}

\author{
Kaveri Nikhil Chougule1, Nikhil P. Chougule2, M. T. Satyanarayana3, Prakash B. Behere ${ }^{4}$ \\ ${ }^{1}$ Senior Resident, Department of Psychiatry, Dr. D. Y. Patil Medical College and Hospital, Kolhapur. \\ ${ }^{2}$ Assistant Professor, Department of Psychiatry, Dr. D. Y. Patil Medical College and Hospital, Kolhapur. \\ 3 Professor and HOD, Department of Psychiatry, Sri Siddartha Medical College, Tumkur. \\ ${ }^{4}$ Vice Chancellor, D. Y. Patil Education Society, (Deemed University), Kolhapur.
}

ABSTRACT
BACKGROUND
Premenstrual symptoms are particularly common in reproductive age groups and therefore represents a significant public health
problem in young girls. This study aims to estimate the prevalence, severity, determinants of premenstrual symptoms among the
female medical and nursing students.

\section{MATERIALS AND METHODS}

This study was conducted in a tertiary hospital and research centre from October 2012 to May 2013. It included 820 medical and nursing students. They filled different questionnaires covering American College of Obstetrics and Gynaecology (ACOG) criteria to diagnose Premenstrual Syndrome (PMS), demographic and reproductive variables. The presented symptoms were compared and analysed using $\mathrm{x} 2$ tests.

\section{RESULTS}

Prevalence of premenstrual symptoms was $97.10 \%$ and prevalence of PMS was diagnosed in $76.83 \%$ of cases. The severity of premenstrual symptoms distributed as $89.21 \%$ mild, $10.04 \%$ moderate and $0.75 \%$ severe. The most frequent psychological symptom was irritability and most frequent somatic symptom was abdominal bloating. Chi square revealed that PMS was significantly associated with regularity of menstrual cycles, age of menarche at 12 or more years, 3 - 6 days of menstrual bleeding and development of premenstrual syndrome.

\section{CONCLUSION}

PMS is a common problem in reproductive age group. Younger student age, urban residence, late age of menarche, regular cycles and moderate menstrual bleed are possible risk factors for PMS.

\section{KEYWORDS}

Phenomenology, Premenstrual Symptoms, Premenstrual Syndrome.

HOW TO CITE THIS ARTICLE: Chougule KN, Chougule NP, Satyanarayana MT, et al. A phenomenological study of premenstrual symptoms in medical and nursing students. J. Evolution Med. Dent. Sci. 2017;6(46):3576-3581, DOI: 10.14260/Jemds/2017/771

\section{BACKGROUND}

From ancient times, various facets of women's personalities, capabilities and moods have been attributed to menstruation and "instability" resulting from women's reproductive cycles has been used to justify denying women equal access to education and employment. ${ }^{1}$

According to Halbreich and Colleagues, women have approximately 481 menstrual cycles during her age span. Although, menstruation is typically a universal event during a woman's reproductive life, and up to $90 \%$ report perceiving one or more symptoms during the days before menstruation. More than 150 premenstrual symptoms have been identified over the last 50 years. ${ }^{2}$

Prevalence ranges from reports that suggest 5\% - 20\% have moderate-to-severe clinically relevant premenstrual

Financial or Other, Competing Interest: None.

Submission 13-05-2017, Peer Review 29-05-2017,

Acceptance 01-06-2017, Published 08-06-2017.

Corresponding Author:

Dr. Kaveri Nikhil Chougule,

Senior Resident,

Department of Psychiatry,

Dr. D. Y. Patil Medical College \& Hospital,

Kolhapur.

E-mail: dr.kaverinc@gmail.com

DOI: $10.14260 /$ jemds/2017/771 complaints and up to $75 \%$ of all women of fertile age may experience symptoms of premenstrual syndrome. ${ }^{3}$

Premenstrual symptoms associated with Premenstrual Syndrome (PMS) may impair the overall physical health of a woman as well as interpersonal relationships, daily routine and work productivity. The cause of the premenstrual experience has progressed from a supposed hormonal imbalance to psychological to a more recent multi-causal origin. ${ }^{4}$

\section{Aims and Objectives}

1. To find out the frequency of premenstrual symptoms in Medical and Nursing college students.

2. To describe the severity of emotional, physical and behavioural symptoms.

\section{MATERIALS AND METHODS}

An observational study, cross-sectional study was conducted in multispecialty teaching hospital during the period of 18 months after obtaining ethical clearance for the study from the Institutional Ethical Committee. The participants were given liberal verbal explanations plus description letters about the topic and the aim of the study with attached consent forms. The respondents were guaranteed confidentiality and anonymity. All the questionnaires were self-reported and completed by the participants. Data was 
collected over by filling 10 items of American College of Obstetrics and Gynaecology (ACOG) assessment criteria after taking consent from Medical and Nursing students. A total of 820 available sample was collected.

\section{Inclusion Criteria}

1. Symptoms should start during the five days before the menses and relieved within four days of the onset of the menses without recurrence until at least cycle day 13.

2. Symptoms should be evident for two consecutive cycles.

3. The reproductive age group of 18 - 40 years.

\section{Exclusion Criteria}

1. Presence of current major gynaecological illness in the past 1 year.

2. Presence of major medical illness like malignancy, chronic infections, etc.

3. Presence of active psychiatric illness including substance abuse.

\section{Instruments Used}

All the Questionnaires was Self-reported and Completed by the Participants-

1. Socio-demographic and reproductive questionnaire consists of 10 items that includes a number of demographic and reproductive variables.

2. Questionnaires based on American College of Obstetrics and Gynaecology (ACOG) PMS diagnostic criteria: Clinical management guidelines for PMS that include diagnostic criteria was published in 2000 by the ACOG. A questionnaire was constructed based on ACOG PMS criteria including the following six behavioural and four somatic symptoms; depression, anger outbursts, irritability, anxiety, confusion and social withdrawal; breast tenderness, abdominal bloating, headache and swelling of extremities. Guidelines for a diagnosis of PMS specified that one or more disturbing affective or somatic symptoms must have occurred during the 5 days before menses in each of 3 previous menstrual cycles. These symptoms must be relieved within 4 days of the onset of menses and must not recur until at least day 13 of the woman's cycle. Participants will be deemed to meet the ACOG for PMS if they rated their experience of at least one of the six behavioural symptoms and one of the four somatic symptoms. .5

To estimate the severity of PMS, each item is rated on a scale of 0 "not at all" to " 3 extreme." The highest score of each symptom in the premenstrual period is calculated. Then the total score of PMS is calculated as the sum of the symptom's score divided by the number of symptoms (mean) and converted to percent. Therefore, the score between $0 \%-33 \%$ represented mild form of PMS, 33\% - 66\% as moderate and more than $66 \%$ is accounted as a severe form of PMS.

\section{Statistical Analysis}

Descriptive analysis was done using different sociodemographic and reproductive variables which were presented, compared and analysed using chi-square tests, wherein $p$ value $<0.5$ was significant.

\section{RESULTS}

Description of the sample characteristics subjects were selected through convenient sampling and a total of 820 women participated in the study. The data obtained were analysed and depicted in below tables and figure.

\begin{tabular}{|c|c|c|}
\hline $\begin{array}{c}\text { Pre-Menstrual } \\
\text { Symptoms }\end{array}$ & Frequency & Percent \\
\hline Absent & 24 & $2.90 \%$ \\
\hline Present & 796 & $97.10 \%$ \\
\hline Total & $\mathbf{8 2 0}$ & $\mathbf{1 0 0 . 0 0 \%}$ \\
\hline Table 1. Frequency of Premenstrual Symptoms \\
\hline
\end{tabular}

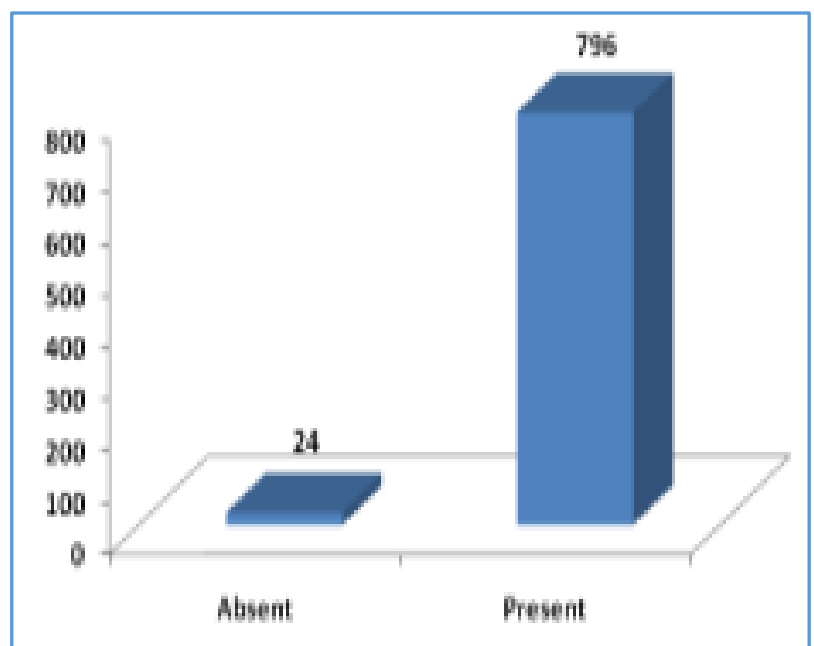

Figure 1. Bar Diagram showing Distribution Frequency of Premenstrual Symptoms

A total of $796(97.10 \%)$ reported of premenstrual symptoms. These were the students who had experienced at least one premenstrual symptoms and remaining $24(2.90 \%)$ did not experience premenstrual symptom at all.

\begin{tabular}{|c|c|c|}
\hline $\begin{array}{c}\text { Premenstrual } \\
\text { Syndrome (PMS) }\end{array}$ & Frequency & Percent \\
\hline Present & 630 & $76.83 \%$ \\
\hline Absent & 190 & $23.17 \%$ \\
\hline Total & $\mathbf{8 2 0}$ & $\mathbf{1 0 0 . 0 0 \%}$ \\
\hline \multicolumn{2}{|c|}{ Table 2. Frequency of Premenstrual Syndrome }
\end{tabular}

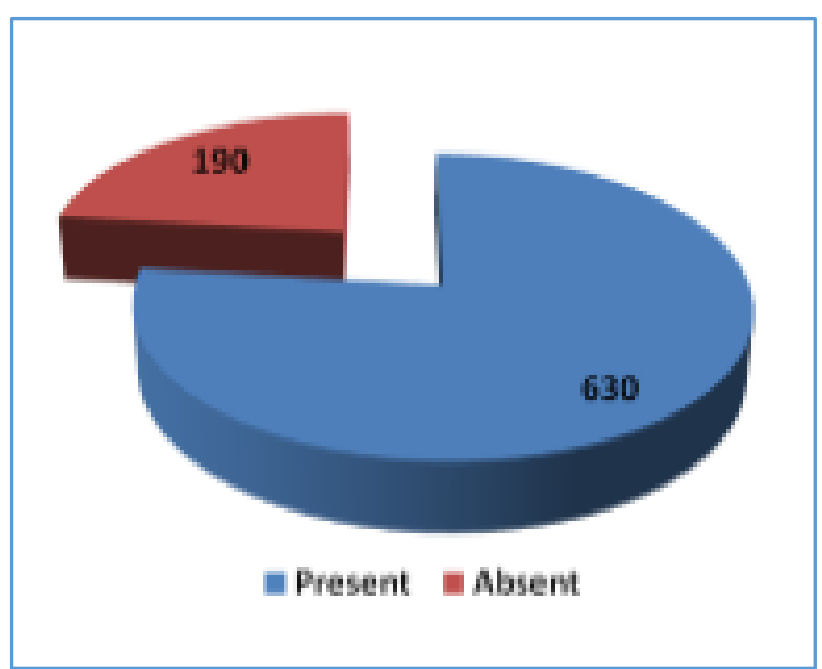

Figure 2. Bar Diagram showing Distribution of PMS 
Premenstrual syndrome was found in 630 (76.83\%) women. These were the students who had experienced at least one somatic and one psychological premenstrual symptoms.

\begin{tabular}{|c|c|c|}
\hline Severity & Frequency & Percent \\
\hline Mild & 711 & $89.21 \%$ \\
\hline Moderate & 80 & $10.04 \%$ \\
\hline Severe & 6 & $0.75 \%$ \\
\hline Total & $\mathbf{7 9 7}$ & $\mathbf{1 0 0 . 0 0 \%}$ \\
\hline \multicolumn{2}{|c|}{ Table 3. Severity of Premenstrual Symptoms }
\end{tabular}

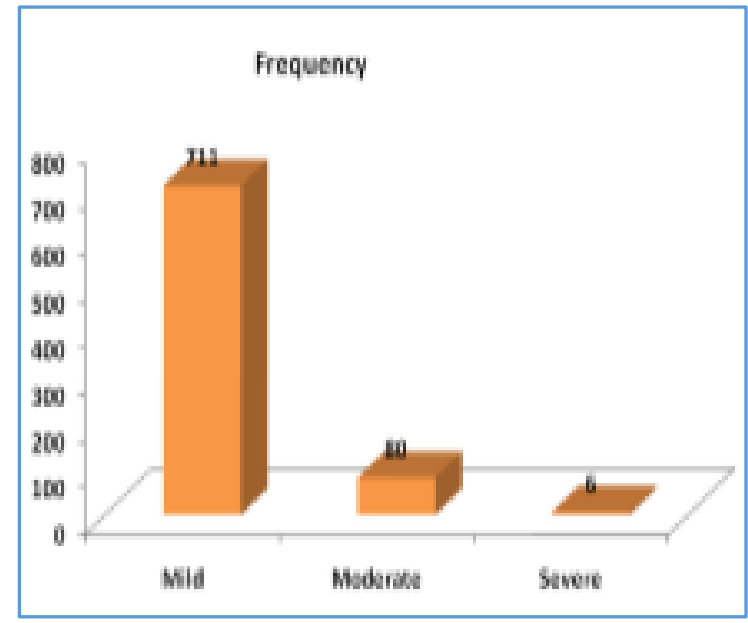

Figure 3. Bar Diagram showing Distribution Based on Severity of PMS

Distribution severity of premenstrual symptoms was as follows: Mild- 711 (89.21\%), Moderate- 80 (10.4\%) and Severe- $6(0.75 \%)$.

\begin{tabular}{|c|c|c|}
\hline Symptoms & Frequency & Percentage \\
\hline Abdominal bloating & 581 & 71 \\
\hline Breast tenderness & 247 & 30 \\
\hline Headache & 279 & 34 \\
\hline Swelling of Extremities & 63 & 7.7 \\
\hline Confusion & 143 & 17 \\
\hline Irritability & 605 & 73.8 \\
\hline Anger Outburst & 314 & 41.6 \\
\hline Anxiety & 216 & 26.4 \\
\hline Depression & 272 & 33.2 \\
\hline Social Withdrawal & 198 & 24 \\
\hline $\begin{array}{r}\text { Table 4. F } \\
\text { Prem }\end{array}$ & $\begin{array}{l}\text { and Ra } \\
\text { Sympto }\end{array}$ & \\
\hline
\end{tabular}

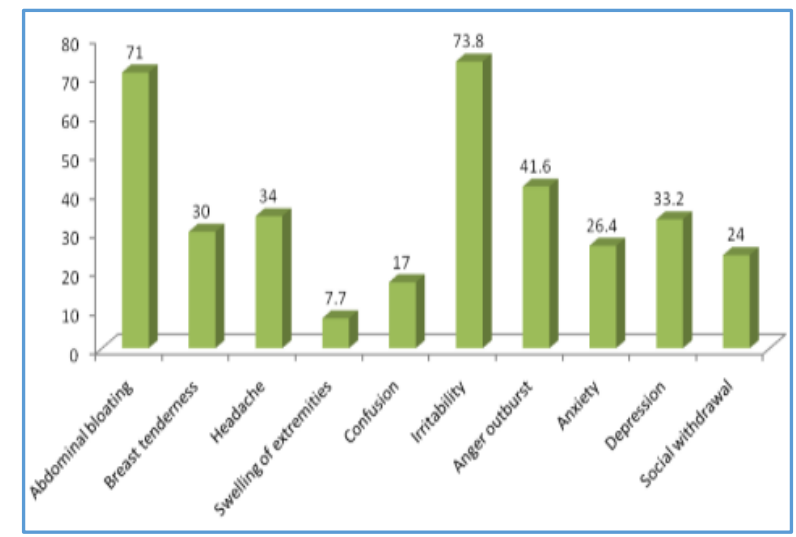

Figure 4. Bar Diagram showing the Distribution Based on Frequency and Ranking of Symptoms
The frequency of somatic symptoms were- Abdominal bloating (71\%), breast tenderness (30\%), headache (34\%) and swelling of extremities (7.7\%). The distribution of affective symptoms- Confusion (17\%), irritability (73.8\%), anger outbursts (41.6\%), anxiety (26.4\%), depression (33.2\%) and social withdrawal (24\%).

\begin{tabular}{|c|c|c|c|}
\hline \multirow{2}{*}{ Course } & \multicolumn{2}{|c|}{ PMS } & Total \\
\cline { 2 - 4 } & Absent & Present & 458 \\
\hline Medical & 123 & 335 & 362 \\
\hline Nursing & 67 & 295 & $\mathbf{8 2 0}$ \\
\hline Total & $\mathbf{1 9 0}$ & $\mathbf{6 3 0}$ & Table 5. Association between PMS and Course of Study \\
\hline
\end{tabular}

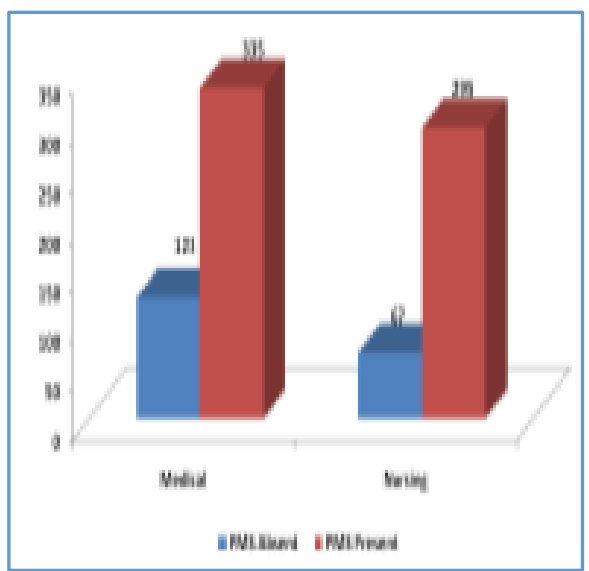

$(\chi 2=7.90$, d.f-1, $\mathrm{p}>0.004)$

Figure 5. Bar Diagram showing Distribution Based on Course of Study vs. PMS

There was significant association between the prevalence of PMS and course of study. This shows that PMS is higher in medical than in nursing students.

\begin{tabular}{|c|c|c|c|}
\hline Age & Absent & Present & Total \\
\hline$<20$ & 83 & 285 & 368 \\
\hline $21-25$ & 88 & 306 & 394 \\
\hline $26-30$ & 18 & 37 & 55 \\
\hline $31-35$ & 1 & 2 & 3 \\
\hline $36-40$ & 0 & 0 & 0 \\
\hline Total & $\mathbf{1 9 0}$ & $\mathbf{6 3 0}$ & $\mathbf{8 2 0}$ \\
\hline \multicolumn{4}{|c}{ Table 6. Association between PMS and Age } \\
\hline
\end{tabular}

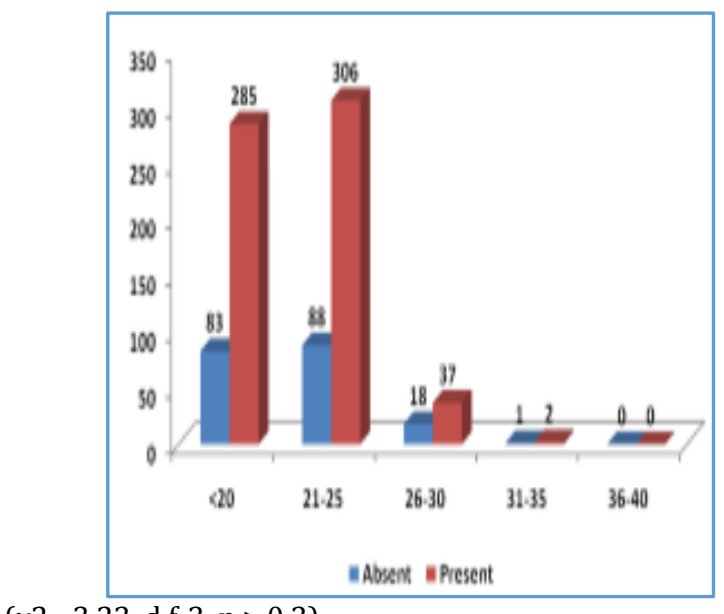

$(\chi 2=3.23$, d.f-3, $\mathrm{p}>0.3)$

Figure 6. Bar Diagram showing the Distribution Based on Age vs. PMS 
There was no significant association between the prevalence of PMS and age. Majority of students with PMS were found in the age group of 18 - 25 years.

\begin{tabular}{|c|c|c|c|}
\hline \multirow{2}{*}{$\begin{array}{c}\text { Age at } \\
\text { Menarche }\end{array}$} & Absent & Present & Total \\
\cline { 2 - 4 }$<12$ years & 57 & 136 & 193 \\
\hline$>12$ years & 133 & 494 & 627 \\
\hline Total & $\mathbf{1 9 0}$ & $\mathbf{6 3 0}$ & $\mathbf{8 2 0}$ \\
\hline \multicolumn{3}{|c|}{ Table 7. Association of PMS and Age at Menarche } \\
\hline
\end{tabular}

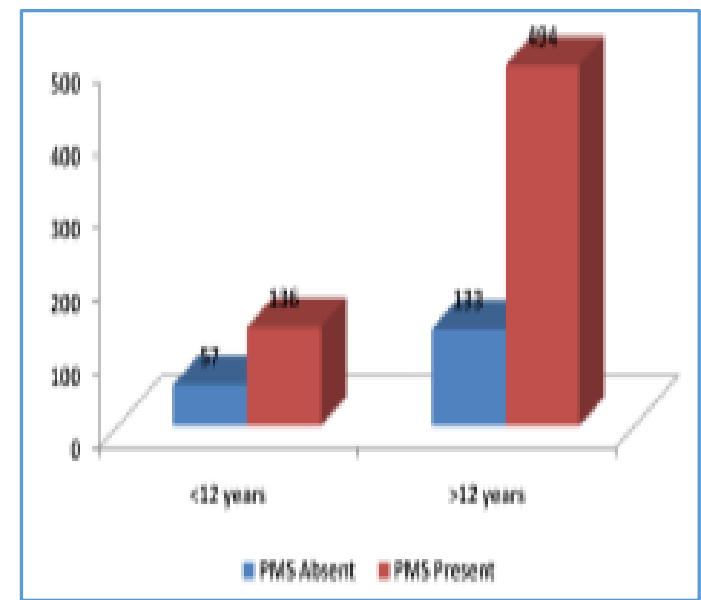

$(\chi 2=5.74$, d.f- $1, \mathrm{p}>0.01)$

Figure 7. Bar Diagram showing the Distribution Based on PMS vs. Age at Menarche

There was statistical significance between the prevalence of PMS and age of menarche. The PMS is higher in students who had their menarche at 12 years or above.

\begin{tabular}{|c|c|c|c|}
\hline \multirow{2}{*}{$\begin{array}{l}\text { Regularity of } \\
\text { Menstruation }\end{array}$} & \multicolumn{2}{|c|}{ PMS } & \multirow[b]{2}{*}{ Total } \\
\hline & Absent & Present & \\
\hline Regular & 161 & 534 & 695 \\
\hline Irregular & 29 & 96 & 125 \\
\hline Total & 190 & 630 & 820 \\
\hline & enstru & ad & ty of \\
\hline
\end{tabular}

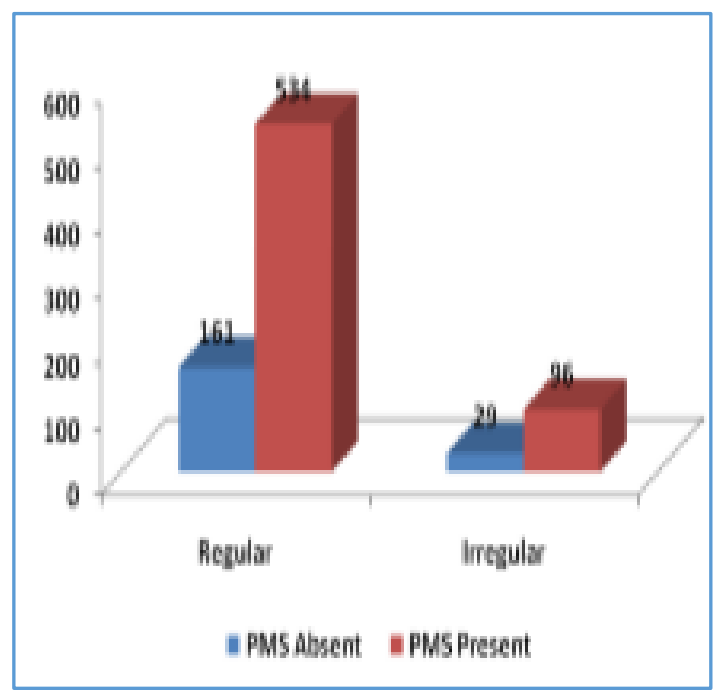

$(\chi 2=00$, d.f $-1, \mathrm{p}>0.99)$

Figure 8. Bar Diagram showing the Distribution Based on PMS vs. Regularity of Menstruation
There was no significant association between the prevalence of PMS and regularity of menstruation, majority of students with regular cycles experienced PMS.

\begin{tabular}{|c|c|c|c|}
\hline \multirow{2}{*}{$\begin{array}{c}\text { Duration of } \\
\text { Menstrual } \\
\text { Bleeding }\end{array}$} & \multicolumn{2}{|c|}{ PMS } & \multirow[b]{2}{*}{ Total } \\
\hline & Absent & Present & \\
\hline$<3$ days & 42 & 90 & 132 \\
\hline 3 - 6 days & 131 & 471 & 602 \\
\hline$>6$ days & 17 & 69 & 86 \\
\hline Total & 190 & 630 & 820 \\
\hline
\end{tabular}

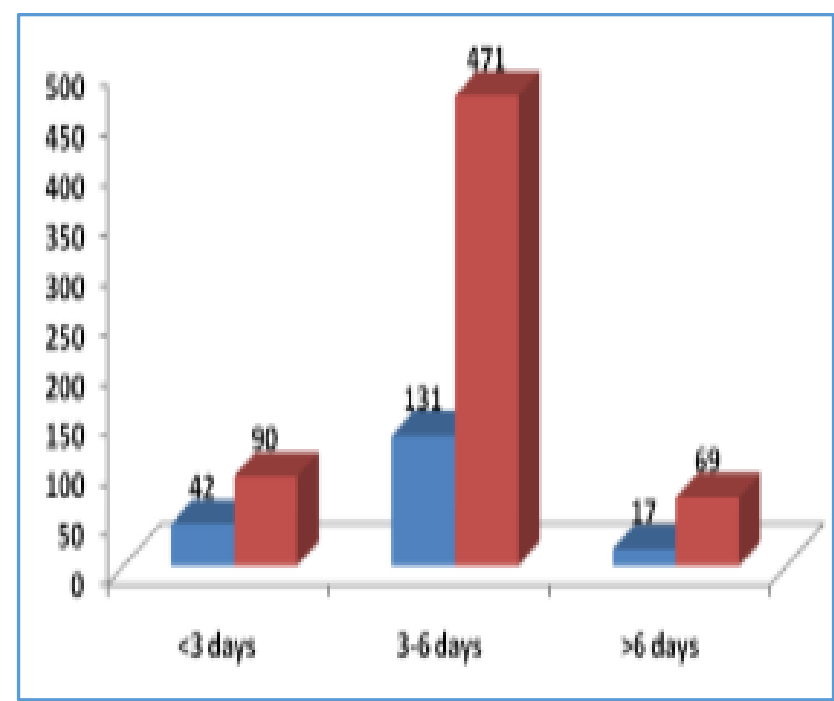

$(\mathrm{x} 2=6.78, \mathrm{~d} . \mathrm{f}-2, \mathrm{p}>0.03)$

Figure 9. Bar Diagram showing the Distribution of PMS and Duration of Menstrual Bleeding

There was significant statistical association between the prevalence of PMS and duration of menstrual bleeding. Thus, PMS was higher in students who had duration of menstrual bleeding for 3 - 6 days.

\section{DISCUSSION}

This study sheds new light on the phenomenology of premenstrual symptoms by estimating the prevalence, severity and symptomatology in a sample of medical and nursing students.

The prevalence of premenstrual symptoms in the present study was $97.10 \%$ and was in accordance to retrospective community surveys that nearly $90 \%$ of women had experienced at least one premenstrual symptoms as defined by ICD-10 criteria. $^{7}$ Many such studies had found premenstrual symptoms in $90 \%$ of a sample or more. Some of these were Prabha Chandra et al (1994) ${ }^{8-}$ 95\%, Sibil Tschudin et al (2010)9-91\% reported at least one mild premenstrual symptoms. However, epidemiological surveys have estimated that as many as $75 \%$ of reproductive age women experience some symptoms attributed to the premenstrual phase of menstrual cycle. According to a report by the Committee on Gynaecologic Practice of the ACOG, up to $85 \%$ of women of reproductive age have physical and psychological changes with menstruation. ${ }^{7}$ The prevalence of premenstrual symptoms in the present study was in accordance with many of the previous studies. 
From the review of literature, a wide variation in the prevalence of PMS has been noted which was ranging from $22 \%$ to $96 \%$. The reported prevalence in our study was $77 \%$, was in agreement with many of the other studies showing high prevalence of PMS. These studies were done by ElDefrawi et al (1990)10- 70\%, Steiner M et al (2006)11- 85\%, Nadeeka K. Chandraratne et al (2011) ${ }^{12}-65.7 \%$ of the subjects.

It was again seen that in some studies the percentage prevalence of PMS was much lower as $25 \%$. A cross cultural investigation conducted in 14 different cultural groups in 10 countries found a lower prevalence rate $(23 \%-34 \%)$ in nonwestern cultures, while a higher prevalence rate $(71 \%-73 \%)$ was reported in the western countries. And according to a report by the Committee on Gynaecologic Practice of the ACOG $20 \%-40 \%$ of them experience symptoms of PMS. Others, it is possible that such variation in the prevalence could be explained on the basis of varied definitions used, methods of data collection, questionnaires used, sampling technique and the cultural background of study population.

The severity of the premenstrual symptoms in the present study was milder in $89.21 \%$, moderate in $10.04 \%$ and severe in $0.75 \%$. This was in agreement with studies of Sternfeld et al $(2002)^{13}$ who had reported the symptoms at frequency of $15.6 \%, 67.1 \%$ and $12.7 \%$ for mild, moderate and severe symptoms respectively; whereas Tabassum et al (2005) ${ }^{14}$ reported $42 \%$ mild, $18.2 \%$ moderate and $31.7 \%$ severe cases. Potter et al (2009) ${ }^{15}$ interviewed 2836 French women and reported $12.2 \%$ of participants with moderate or severe PMS; whereas Magdy Hassan Balaha et al (2010) ${ }^{16}$ frequency as measured by $\mathrm{ACOG}^{7}$ were allocated as $45 \%$ mild, $32.6 \%$ moderate and $22.4 \%$ severe cases. The only important finding that was seen in our study as compared to many other studies on severity of PMS was that lower incidence of severe symptoms and higher incidence of milder symptoms. The lower reporting of severe symptoms as opposed to much higher reporting of milder symptoms could be due to the fact that over years the awareness of the general population of such symptoms has substantially increased due to better education and increasing empowerment of women in general. Additionally, acceptance of the fact that experiencing premenstrual symptom as part of body physiology could be another reason.

In the current study, the frequency of somatic symptoms were abdominal bloating (71\%), headache (34\%), breast tenderness (30\%) and swelling of extremities (7.7\%); whereas the distribution of affective symptoms were irritability (73.8\%), anger outbursts (41.6\%), depression (33.2\%), anxiety $(26.4 \%)$, social withdrawal $(24 \%)$ and confusion $(17 \%)$. Thus, most common affective symptom was irritability (73.8\%). This was in accordance to some of the previous studies, where the psychological symptom severity was in agreement to the present study. These were, Mak K. Yet et al (1985) ${ }^{17}$ reported, irritability $(60 \%)$ as most common presentation. However, Prabha S. Chandra et al in $(1994)^{8}$ reported lethargy (30\%), lack of desire to work (25\%), restless and irritability (23\%). ACOG ${ }^{9}$ in its annual review had summarised the findings of many previous studies and had mentioned irritability as the common reported symptom. Freeman et al (2003) ${ }^{18}$ had summarised depression (56\%) as most common and irritability (48\%) as the second most.

In the present study, abdominal bloating (71\%) was most common somatic symptom. This was in agreement with the studies of Mak K. Yet et al (1985) ${ }^{17}$ who reported abdominal bloating (42\%) followed by headache (13\%). However, Prabha S. Chandra et al in (1994) $)^{8}$ mentioned stomach ache $(50 \%)$, backache $(38 \%)$, headache $(37 \%)$, acne $(32 \%)$ as most frequent presentation. According to Magdy Hassan Balaha et al (2010), the most frequently reported symptom was abdominal bloating (75.3\%). According to Zehra Sitwat et al (2013),19 the frequent symptoms were breast tenderness $(67.65 \%)$ than abdominal blotting $(47.06 \%)$ Shruti Brahmbhatt et al (2013) ${ }^{12}$ reports $68 \%$ suffered with backache, $64 \%$ leg cramps, $62 \%$ fatigue and breast tenderness. The standardised tool ACOG criteria for PMS used in the current study had only 10 symptoms (4 somatic and 6 psychological), which had no scope for the subjects to report possibly other existing symptoms. The other difference between could be due to different cultural and sociodemographic variables.

Many factors were statistically analysed in this study as predictors of PMS. They were course of study, age groups, age of menarche, regularity of cycles and duration of menstrual bleeding.

PMS had a significant association with younger age groups in our study. This is in agreement with some of the studies. They were Freeman EW et al (1997), ${ }^{18}$ Halberich U et al $(1982)^{2}$ found that symptoms were more intense in the 16 - 18 years, Delara et al (2012)20 14 - 19 years, Magdy Hassan Balaha et al (2010)16 15 - 20 years, Prabha Chandra et al (1994)8- 35 - 45 years. The difference in occurrence of PMS at different ages reported above may not be significant, as most groups were of lower age range rather than women of older reproductive age.

In the current study, there was clear association between regularity of menstrual cycles, age of menarche at 12 years or more years, 3 - 6 days of menstrual bleeding and development of PMS. These findings were consistent with findings of some previous investigators like Steiner M (2006), Magdy Hassan Balaha et al (2010).16 On the contrary, others did not find any association between PMS and age at menarche, El-Defrawi MH et al (1990) ${ }^{10}$ and Samia Tabassum (2005). ${ }^{14}$ The findings in our study could be explained with the fact that age of menarche and regular cycles are associated with early establishment of ovarian functions and ovulation with fluctuation of steroid hormones in such a young age with less physical and psychological maturity may lead to PMS manifestations.

\section{Limitations of this Study}

1. This study included a selective population sample comprising of medical and nursing students from one academic institute, which may limit the generalisability of the findings.

2. Because of the cross-sectional design of the study, we are unable to determine longitudinal relations between any of the studied predictors and outcome and whether they were coexisting or pre-existing.

3. The current study was a retrospective analysis using questionnaires, as it was inherently difficult to use the prospective approaches. 
4. Despite the questions asked were standardised and had been used in many previous studies, we however believe that the questionnaire filling is likely to pose some bias, because of problem of recall or a subjective tendency of the study sample to over- or under-reports of the symptoms.

\section{CONCLUSION}

Premenstrual symptoms and premenstrual syndromes are common problems in young students in this part of the world. Younger age groups, medical students, regularity of menstrual cycles, age of menarche at 12 years or more years and 3 - 6 days of menstrual bleeding could be considered as predictors for PMS. Further studies on population with preferably prospective approach need to be conducted to confirm these results and to plan out strategies for better detection and management of PMS in young women. Severe PMS may be associated with more premenstrual symptoms, impairment of daily activities and psychological distress symptoms. The introduction of a reproductive health component into college health education program could help in providing information, education and support to the young students. Also, Introduction, Education and Communication (IEC) about the importance of sex education and scientific basis of reproductive health to the general population would be beneficial.

\section{REFERENCES}

[1] Delaney J, Lupton MJ, Toth E. The curse: a cultural history of menstruation. New York: E.P. Dutton 1976.

[2] Halbreich U, Endicott J, Schacht S, et al. The diversity of premenstrual changes as reflected in the premenstrual assessment form. Acta Psychiatric Scand 1982;65(1):46-65.

[3] Campagne DM, Campagne G. The premenstrual syndrome revisited. European Journal of Obstetrics \& Gynecology and Reproductive Biology 2007;130(1):417.

[4] Yonkers KA, O'Brian S, Eriksson E. Premenstrual syndrome. Lancet 2008;371(9619):1200-10.

[5] American College of Obstetricians and Gynecologists. ACOG practice bulletin: premenstrual syndrome. Int J Gynecol Obstet 2001;73:183-91.

[6] American College of Obstetricians and Gynecologists (ACOG). Premenstrual syndrome. ACOG, Washington, DC 11 2000:15.

[7] World Health Organization (WHO). International statistical classification of disease and health related problems. 10th revision (ICD -10). Geneva: WHO 1992.

[8] Chaturvedi SK, Chandra PS, Beena MB, et al. Prevalence of premenstrual symptoms and syndromes: preliminary observations. Nimhans Journal 1994;12(1):9-14.
[9] Tschudin S, Bertea PC, Zemp E. Prevalence and predictors of premenstrual syndrome and premenstrual dysphoric disorder in a populationbased sample. Arch Womens Men Health 2010;13(6):485-94.

[10] El-Defrawi MH, Lotfi G, Mahfouz R. Late luteal phase dysphoric disorder, do we need another psychiatric category. Egyptian Journal of Psychiatry 1990;13: 205-12.

[11] Steiner M, Pearlstein T, Cohen LS, et al. Expert guidelines for the treatment of severe PMS, PMDD, and comorbidities: the role of SSRIs. Journal of Women's Health 2006;15(1):57-69.

[12] Chandraratne NK, Gunawardena NS. Premenstrual syndrome: the experience from a sample of Sri Lankan adolescents. Journal of Pediatric and Adolescent Gynecology 2011;24(5):304-10.

[13] Sternfeld B, Swindle R, Chawla A, et al. Severity of premenstrual symptoms in a health maintenance organization population. Obstet Gynecol 2002; 99 (6): 1014-24.

[14] Tabassum S, Afridi B, Aman Z, et al. Premenstrual syndrome: frequency and severity in young college girls. J Pak Med Assoc 2005;55(12):546-9.

[15] Potter J, Bouyer J, Trussell J, et al. Premenstrual syndrome prevalence and fluctuation over time: results from a French population-based survey. Journal Of Women's Health 2009;18(1):31-9.

[16] Balaha MH, Amr MA, Al Moghannum MS, et al. The phenomenology of premenstrual syndrome in female medical students: a cross sectional study. Pan Afr Med J 2010; 5: 4.

[17] Mak KY, Kitty KC. Premenstrual tension in a psychiatric patient population in Hong Kong. Journal of Hong Kong Coll Gen Pract 1985;7:1449-55.

[18] Freeman EW, Sondheimer SJ. Premenstrual dysphoric disorder: recognition and treatment. Primary Care Companion J Clin Psychiatry 2003;5(1):30-9.

[19] Sitwat Z, Abid A, Arif A, et al. Premenstrual syndrome symptoms (PMS) and prevalence among university students in Karachi, Pakistan. Int Res J Pharm 2013;4(4):113-6.

[20] Cleckner-Smith CS, Doughty AS, Grossman JA. Premenstrual symptoms. Prevalence and severity in an adolescent sample. J Adolese Health 1998; 22 (5): 403-8. 